\title{
Micorrizas Arbusculares del Sur de la Amazonia Colombiana y su Relación con Algunos Factores Fisicoquímicos y Biológicos del Suelo
}

\author{
Clara Patricia PENAA-VENEGAS ${ }^{1}$, Gladys Inés CARDONA, Jorge Humberto ARGUELLES, Adriana Lucia \\ ARCOS
}

\begin{abstract}
RESUMEN
La presencia de micorrizas arbusculares en la vegetación de la Amazonia mejora la nutrición de las plantas en suelos de baja fertilidad. Este trabajo evaluó la presencia natural de hongos micorrícicos de tipo arbuscular (HMA) en suelos ácidos de textura franco-arcillosa a arcillosa del sur de la Amazonia colombiana bajo bosque, rastrojo joven, y praderas establecidas, a dos profundidades diferentes. Fue estudiada la presencia de HMA (riqueza y abundancia de esporas) relacionado con la acidez, la capacidad de intercambio catiónico, el carbono orgánico, el fósforo total, las fracciones de fósforo soluble y fijado al aluminio, hierro y calcio, y el ADN total del suelo. Se detectaron diferencias significativas, en el contenido de ADN total y el número de esporas respecto a la profundidad de muestreo. El pH presentó un efecto significativo sobre el contenido de ADN y el número de esporas de HMA. El contenido de ADN en el suelo se vio afectado por las concentraciones de fosfatos de aluminio, mientras la esporulación de HMA fue afectada por las concentraciones de fosfatos de hierro del suelo. Así, el número de esporas de HMA en suelos de la Amazonia se ve afectada por la profundidad, el pH y por el tipo de fosfatos minerales presentes.
\end{abstract}

PALABRAS CLAVE

Micorriza arbuscular, Amazonia colombiana, Oxisoles, Fósforo, ADN total.

\section{Micorrizas arbusculares no sul da amazônia colombiana e sua relação com algumos fatores fisicoquímicos e biológicos do solo}

\begin{abstract}
RESUMO
A presença das micorrizas arbusculares na vegetação da Amazônia pode incrementar a nutrição das plantas nos solos com baixa fertilidade. Neste estudo foi avaliada a ocorrência natural de fungos formadores de micorriza arbuscular (MA) em solos ácidos de textura argilosa no sul da Amazônia colombiana, considerando-se nas coberturas de floresta nativa, floresta secundaria jovem, e pastagens estabelecidas e duas profundidades. Foi estudada a ocorrência das MA (riqueza e abundância de esporos) com relação à: acidez, capacidade de troca de cátions, carbono orgânico, fósforo total, frações de fósforo solúvel, fraçōes fixadas ao alumínio, ferro e cálcio e DNA total do solo. Quanto à profundidade, encontraram-se diferenças significativas, tanto para o conteúdo de DNA total e ao número de esporos. Entre as variáveis químicas o $\mathrm{pH}$ teve efeito significativo sob o conteúdo de DNA e o número de esporos dos fungos MA. O conteúdo de DNA foi influenciado pelas concentraçōes de fosfatos de alumínio do solo, em quanto a esporulação de fungos MA foi influenciada pelas concentrações de fosfatos de ferro. Concluiu-se que a abundância dos fungos MA variou dependendo da profundidade do estrato avaliada, o $\mathrm{pH}$ e os fosfatos minerais presentes no solo.
\end{abstract}

PALAVRAS-CHAVE

Micorrizas arbusculares, Amazônia colombiana, Oxissolos, Fosforo, ADN total.

Instituto Amazónico de Investigaciones Científicas Sinchi. Avenida Vásquez-Cobo Calle 15 y 16, Leticia, Amazonas, Colombia. Tel: (098) 5925481.

e-mail: cpena@sinchi.org.co 


\section{INTRODUCCION}

Los Oxisoles y Ultisoles caracterizados por su alta acidez y baja fertilidad natural, se constituyen en los suelos predominantes de la cuenca amazónica (Cuevas, 2001), siendo el 95\% de los suelos de la región amazónica colombiana. Allí el fósforo con frecuencia es el elemento limitante de la fertilidad suelo (Howeler y Sieverding, 1982; Vitousek, 1984; Schlesinger, 1997), el cual proviene casi exclusivamente de la descomposición de la materia orgánica. El acceso de las plantas a los fosfatos es limitada y depende en gran medida de las características de su sistema radical, el cual determina la eficiencia en la exploración y absorción del fósforo. En plantas con un sistema radical poco desarrollado, esta limitación puede ser superada si es establecida una simbiosis con hongos formadores de micorrizas (Howeler y Sieverding, 1982; Dodd et al., 1990; Diederichs y Moawad, 1993).

Las micorrizas arbusculares son la forma de micorriza mas ampliamente distribuida en la Amazonia. De allí, la importancia de estudiarla con relación a diferentes factores que la pueden afectar. Factores como la acidez, y las concentraciones de materia orgánica, fósforo, nitrógeno, aluminio, cobre y zinc en el suelo, inciden sobre el buen establecimiento y desempeño de la simbiosis, lo cual se refleja en la capacidad de colonización de hospederos y la producción de esporas de los hongos (Janos,, 1983; Sieverding 1984; Bhatia et al., 1996). Según Cuenca et al. (2001), aún cuando la tolerancia de las micorrizas a la acidez y los altos niveles de aluminio es aún un tema controversial, en suelos ácidos tropicales tipo Ultisol estos factores no parecen afectar el desempeño de las micorrizas arbusculares nativas, inclusive pudiendo el hongo acumular aluminio en su micelio, vesículas y células auxiliares. Sin embargo, para los Oxisoles de la Amazonia, la información sobre el comportamiento de las micorrizas en relación con factores fisicoquímicos aún no es clara.

En la Amazonia, la profundidad ha sido otro factor evaluado con relación a la simbiosis micorriza arbuscular, dada la generalizada formación de un sistema radicular superficial de las plantas. Al igual que Janos (1996) lo reportó para suelos tropicales, St. John (1980) encontró para suelos de la Amazonia brasileña una alta frecuencia de plantas micorrizadas, en las cuales la mayor colonización ocurría en raicillas ubicadas en los primeros $10 \mathrm{~cm}$ del suelo. El trabajo de St. John no incluyó el recuento de propágulos, ni las especies de hongos formadores de micorrizas arbusculares (HMA) asociadas, por cuanto aún falta mucha información al respecto.

La relación de los HMA con grupos de organismos menos estudiados o con la comunidad total del suelo ha sido pobremente abordada, en parte por las limitaciones de estudiar microorganismos no cultivables o de difícil recuperación en el laboratorio. En los últimos años el estudio de microorganismos del suelo se viene abordando a partir del uso de metodologías de cultivo independiente, en especial para suelos poco estudiados como los de la Amazonia (Borneman y Triplett, 1997). El uso de la cuantificación de ADN total como una medida indirecta de la abundancia de una población en el suelo ha sido abordada por algunos autores (Johnsen et al., 1999; Martin-Laurent et al., 2001). Aún cuando la recuperación de $\mathrm{ADN}$ del suelo tiene limitaciones como medida de abundancia de una comunidad, dado que no se puede garantizar el 100\% de lisis de las células en la muestra, o que no ocurra una sorción del ADN en las partículas de suelo (Martin-Laurent et al., 2001), o que no se de una interferencia de los compuestos húmicos y fenólicos con las lisozimas (Picard et al., 1992; CHO et al., 1996), se puede asumir un error constante de procedimiento que nos permite comparar resultados de muestras de suelo diferentes, con menos sesgo que el obtenido por métodos cultivo dependientes que solo recobran en promedio el $1 \%$ de la microbiota total de una muestra (Martin-Laurent et al., 2001). La relación de HMA con la comunidad edáfica en suelos amazónicos hasta el momento no ha sido abordada, por cuanto es necesario explorar metodologías que permitan su estudio.

Este trabajo contribuye a un mejor entendimiento de la simbiosis micorriza arbuscular en suelos de la Amazonia, con base en el estudio de las esporas de hongos Glomales, y su relación con algunas características físicas, químicas y biológicas del suelo del sur de la Amazonia colombiana.

\section{MATERIAL Y METODOS}

\section{FASE DE CAMPO}

Los datos se obtuvieron a partir de un muestreo de suelos realizado en el mes de agosto de 2001, en el sur del denominado Trapecio amazónico colombiano, sobre planicies disectadas ubicadas entre los $3^{\circ} 46^{\prime} 0.22^{\prime \prime}$ y los $3^{\circ} 58^{\prime} 37.3^{\prime \prime}$ de latitud sur, y entre los $70^{\circ} 09^{\prime} 0.1^{\prime \prime}$ y los $70^{\circ} 20^{\prime} 43.4^{\prime \prime}$ de longitud oeste. Allí se ubicaron cinco bosques maduros poco intervenidos, cinco rastrojos maduros los cuales tenían entre 5 y 8 años de recuperación natural, y cinco praderas de gramíneas con ganadería. Ninguno de los bosques, rastrojos o praderas tenía conexión con otro incluido en el muestreo. En cada uno de ellos, se seleccionó un área de una Ha para el muestreo, se trazó una diagonal imaginaria que atravesara el área de muestreo y sobre esta se ubicaron tres puntos equidistantes para la toma de muestras. De cada unidad de muestreo se tomó una muestra compuesta de $200 \mathrm{~g}$ de suelo para su análisis físico y químico. Igualmente se tomaron muestras a dos (2) profundidades $(0-20 \mathrm{~cm}$ y $20-30 \mathrm{~cm})$, obteniendo un total de 90 muestras para el estudio.

\section{FASE DE LABORATORIO}

Las muestras de suelo fueron transportadas y almacenadas bajo refrigeración hasta realizar los diferentes análisis. Las 
muestras compuestas fueron enviadas al Laboratorio de Suelos del Instituto Geográfico Agustín Codazzi, Bogotá-Colombia para realizar los respectivos análisis fisicoquímicos. El análisis de las muestras incluyó textura (por granulometría), acidez (pH en agua 1:1), capacidad de intercambio catiónico (usando acetato de amonio normal y neutro para su determinación), carbono orgánico (método de Walkley - Black), fósforo total, y fracciones de fósforo soluble y fijado al aluminio, hierro y calcio (Bray II).

En los laboratorios del Instituto Sinchi se realizaron los análisis de dos de los componentes biológicos del suelo: (a) la extracción y cuantificación del ADN total como medida de la abundancia biológica del suelo, y (b) el aislamiento, cuantificación y descripción de esporas HMA como medida del estado de las relaciones microorganismo-planta, relacionada con la fertilidad del suelo y la cobertura vegetal.

\section{EXTRACCIÓN Y CUANTIFICACIÓN DE ADN TOTAL}

Para la extracción de ADN total, se realizó un lavado preliminar de las muestras con buffer TRIS-EDTA pH 8.0 y se conservaron a $-70^{\circ} \mathrm{C}$ hasta el momento de la extracción. El procedimiento de extracción se basó en el utilizado por Wenzl et al. (1997) con algunas modificaciones que han permitido obtener una buena concentración de ADN comunitario de muestras naturales de suelos ácidos, arcillosos, ricos en compuestos orgánicos. El procedimiento detallado es el siguiente: A partir de $5 \mathrm{~g}$ de suelo se realizó el lavado con $30 \mathrm{ml}$ de buffer TRIS-EDTA pH 8.0. Se centrifugó a 6000rpm por $1 \mathrm{~h} 10^{\prime}$ a $4^{\circ} \mathrm{C}$. Al precipitado se le agregó $2.5 \mathrm{ml}$ de buffer de extracción ( $\mathrm{NaCl} 0.5 \mathrm{M}$, Tris $0.05 \mathrm{M}$, EDTA $0.05 \mathrm{M} \mathrm{pH} .3)$, y solución de lisozima. Se incubó a $37^{\circ} \mathrm{CX} 1 \mathrm{~h}$., se agregó $140 \mathrm{ul}$ de SDS al 20\% y se mezcló. Se adicionó $50 \mathrm{ul}$ de proteasa potásica y se incubó a $37^{\circ} \mathrm{CX} 1 \mathrm{~h}$. Se adicionó $5 \mathrm{ml}$ de buffer SDS de extracción y 700ul de SDS al 20\%, se incubando a $65^{\circ} \mathrm{C}$ X 15 min. y luego a $-80^{\circ} \mathrm{C}$. Los últimos dos pasos se repitieron tres veces para completar un tiempo total de $45 \mathrm{~min}$. Se centrifugó a $12.500 \mathrm{rpm} X 30 \mathrm{~min}$ a $4^{\circ} \mathrm{C}$. Al sobrenadante se le adicionó $2.43 \mathrm{ml}$ de $\mathrm{NaCl} 0.5 \mathrm{M}$, seguido de $1.4 \mathrm{ml}$ de CTAB previamente calentado y se incubó a $65^{\circ} \mathrm{CX} 40 \mathrm{~min}$. Se adicionó $50 \mathrm{ml}$ de cloroformo y se centrifugó a 3000rpm X 30 $\mathrm{min}$. Se tomaron $30 \mathrm{ml}$ de la fase superior y se le adicionaron $5 \mathrm{ml}$ de PEG 50\%. Se precipitó toda la noche a $4^{\circ} \mathrm{C}$.

$\mathrm{Al}$ día siguiente se centrifugó a $15000 \mathrm{rpm} X 1 \mathrm{~h} 30^{\prime}$ a $4^{\circ} \mathrm{C}$, se lavaron los pellets con etanol y se centrifugó a $15000 \mathrm{rpm}$ $\mathrm{X} 30 \mathrm{~min}$ a $4^{\circ} \mathrm{C}$. El pellet se disolvió en $240 \mathrm{ul}$ de TE, se adicionó 200ul de PCI, y se centrifugó a 14000rpm X 20 min. Al sobrenadante se le adicionó 200ul de CI y se centrifugó a 14000rpm X 20min. Se llevó a un volumen de 500ul con TE, mas $110 \mathrm{ul}$ de acetato de potasio $3 \mathrm{M}$ y se dejó reposar por $15 \mathrm{~min}$ a temperatura ambiente. Luego se centrifugó a 10000rpm X 10min, se adicionó 500ul de isopropanol frío y se incubó a $-20^{\circ} \mathrm{CX} 2 \mathrm{~h}$. Se centrifugó a $14000 \mathrm{rpm} X 20 \mathrm{~min}$, se lavó con etanol al 70\% y se centrifugó a 14.000rpm X $5 \mathrm{~min}$.

El pellet se disolvió en 20ul de TE. El ADN total extraído se limpio con una solución de $\mathrm{CaCl}_{2}$, Fenol, Cloroformo, Alcohol isoamílico 25:24:1 y se llevó a geles de agarosa al $0.8 \%$ para visualizar y cuantificar las bandas por fluorometría con patrones de peso molecular conocidos.

\section{AISLAMIENTO, CUANTIFICACIÓN Y DESCRIPCIÓN DE ESPORAS DE HMA}

El estudio se realizó a partir $10 \mathrm{~g}$ de suelo con tres repeticiones. Las esporas se separaron mediante el método de tamizado húmedo, seguido por una centrifugación en un gradiente sacarosa al 50\% (w/v), según la metodología sugerida por Gerdemann y Nicolson (1963). Las esporas fueron cuantificadas y separadas por morfotipos para determinar la riqueza de HMA como un estimativo de la abundancia y diversidad de sus poblaciones. Los morfotipos fueron separados a partir del reconocimiento de parámetros morfológicos de las esporas, usados en taxonomía de Glomales, como el color, tamaño, forma de las esporas, las características de sus paredes (grosor, color, presencia de ornamentaciones y reacción Melzer), presencia de célula suspensoria y conexión hifal. Para el estudio de las características morfológicas, las esporas se montaron en lactoglicerina, polivinil-lactoglicerina (PVLG) y PVLG mas Melzer (1:1 v/v). La confirmación de los géneros y las especies se realizó a partir de la comparación de los morfotipos con los reportados en los manuales para identificación de Schenk \& Pérez (1988) y The International Culture Collection of Arbuscular Mycorrhizal Fungi - INVAM (2003), mas la comparación directa de montajes en lámina de vauchers plenamente caracterizados, para lo cual se contó con el apoyo del banco de referencia existente en el Laboratorio de Suelos del Instituto Venezolano de Investigaciones Científicas (IVIC).

\section{PROCESAMIENTO ESTADÍSTICO DE LOS DATOS}

Para establecer el efecto de las coberturas sobre las diferentes variables evaluadas, se realizaron análisis de varianza, mediante la utilización del procedimiento ANOVA del paquete estadístico SAS. Para asegurar normalidad en la distribución de los datos, fue necesario realizar transformaciones de tipo logarítmico de los valores de ADN y número de esporas; la transformación raíz cuadrada se utilizó para el número de morfotipos por muestra y la arcoseno para los datos de carbono orgánico, fracciones de fósforo y morfotipos de micorrizas, expresados en porcentaje. Para complementar estos análisis se ejecutaron pruebas de comparación múltiple de Tukey $(\alpha=0.10)$. 
Para establecer las variables químicas que más afectan el comportamiento microbiológico del suelo, se ajustaron modelos de regresión lineal múltiple, mediante el procedimiento STEPWISE, del paquete estadístico antes mencionado.

\section{RESULTADOS Y DISCUSION}

\section{COMPOSICIÓN FISICOQUÍMICA DE LOS SUELOS Y SU RELACIÓN CON EL TIPO DE COBERTURA}

Los suelos evaluados presentaron una textura entre francoarcillosa y arcillosa (Tabla 1). El análisis de varianza realizado para las variables químicas del suelo, solo detectó diferencias estadísticamente significativas, para el carbono orgánico $(\alpha=0.05)$ y fósforo soluble $(\alpha=0.1)$. La menor concentración de C orgánico se detectó en los suelos con cobertura de rastrojo $(0.70 \%)$, la cual difiere significativamente de la encontrada en suelos de bosque (1.21\%), pero no de suelos de pradera (0.98). Para el P soluble, los suelos bajo rastrojo presentaron la mayor concentración media $(5.14 \%)$, valor que fue estadísticamente igual al encontrado para los suelos con cobertura boscosa (4.71\%), pero significativamente diferente al valor estimado para los suelos de pradera (3.64\%) (Tabla1).

Las diferencias en la composición fisicoquímica de los suelos con diferente cobertura se explican por el estado de desarrollo de la vegetación y la cantidad de materia orgánica en el suelo. La cantidad de materia orgánica depende del balance entre la producción primaria y la tasa de descomposición. Los aportes de hojarasca en los suelos bajo bosque o rastrojo pueden ser similares. Sin embargo, los estados de sucesión tempranos como los rastrojos presentan tasas de crecimiento más dinámicas, lo cual hace que asimile rápidamente mayores cantidades de carbono (Saldarriaga, 1991). Las plantas en estado de crecimiento segregan además mayores cantidades de exudados y enzimas que participan en la descomposición de la materia orgánica, aumentando las concentraciones de fósforo soluble en el suelo. En los suelos de pradera, el carbono orgánico aumenta por la presencia de las raíces finas de las gramíneas que se incorporan a la muestra, como se demuestra al no encontrar diferencias significativas $(\propto=0.10)$ en la cantidad de ADN obtenido entre las muestras de suelo con pradera $(44.1 \mathrm{ng} / \mathrm{g})$, bosque $(38.6 \mathrm{ng} / \mathrm{g})$ y rastrojo $(38.5 \mathrm{ng} / \mathrm{g})$, que puedan atribuirse a un componente biótico en aumento. Igualmente en las praderas no existe un suministro permanente de litter como en las otras coberturas, el nivel de fósforo soluble es bajo, siendo la mayor parte del fósforo fijado en las arcillas en forma mineral (Tabla 1).

\section{ADN TOTAL Y MICORRIZAS ARBUSCULARES DEL SUELO}

La diferencia entre el número de esporas recuperadas de muestras superficiales y profundas de suelo fueron estadísticamente significativas $(\propto=0.1)$. Un número mayor de esporas en los primeros $20 \mathrm{~cm}$ del suelo, superó en más de $400 \%$ la concentración detectada entre los 20 y $30 \mathrm{~cm}$ de profundidad (Tabla 2). Esta diferencia también influye en la cantidad de morfotipos recuperados por muestra, ya que al recuperar un número abundante de esporas en la fase superficial del suelo, también se incrementan las posibilidades de encontrar esporas de hongos micorrícicos poco representativas en la muestra. Es así que en muestras de suelo superficiales se recuperaron 4 morfotipos en promedio, mientras que de muestras profundas se recuperan menos de tres (Tabla 2).

El número de morfotipos recuperados de acuerdo a la profundidad no varió significativamente. Sin embargo, la composición micorrícica de las dos profundidades no fue la misma: Glomus sp2 y Glomus viscosum solo fueron recuperadas de muestras superficiales de suelo, mientras Glomus manihotis, Acaulospora tuberculata, Scutellospora pellucida y Gigaspora sp. solo se recuperaron en muestras de suelo profundo (Tabla 3). En general, es reconocido que los HMA se establecen en la rizosfera. Mientras las condiciones del hospedero y del suelo sean adecuadas, estos se establecerán y esporularán. Por eso, las diferencias encontradas entre profundidades pueden estar relacionadas con la composición florística de cada cobertura, que determina el tipo de hospedero para las micorrizas y las particularidades del sistema radicular de las mismas, que determinaría la profundidad a la cual se establece y esporulan los HMA.

Se pudieron detectar diferencias estadísticamente significativas $(\alpha=0.10)$ entre la cantidad de ADN presente en la parte superficial y en la parte profunda del suelo (Tabla 2). En los primeros $20 \mathrm{~cm}$ de suelo, se concentró más del doble de la cantidad de $A D N$, que el detectado entre los 20 y $30 \mathrm{~cm}$. La mayor presencia biológica en los $20 \mathrm{~cm}$ superficiales del suelo, ocurre donde también crecen y se desarrollan la mayoría de las raíces absorbentes, se acumula y transforma la materia orgánica, y se liberan nutrientes, lo cual está relacionado con la

Tabla 1 - Composición fisicoquímica de los suelos del sur de la Amazonia colombiana bajo tres coberturas diferentes

\begin{tabular}{|c|c|c|c|c|c|c|c|c|c|c|}
\hline COBERTURA & Textura & $\mathrm{pH}$ & Co $(\%)$ & CIC (meq/100g) & Pt (ppm) & Ps (ppm) & Po (ppm) & PAl (ppm) & PFe (ppm) & PCa (ppm) \\
\hline Pradera & Ar-Far & $4.78 \mathrm{a}$ & $0.98 \mathrm{ab}$ & $19.10 \mathrm{a}$ & $398.56 \mathrm{a}$ & $3.64 \mathrm{~b}$ & $206.28 \mathrm{a}$ & $3.22 \mathrm{a}$ & $53.14 \mathrm{a}$ & $6.54 \mathrm{a}$ \\
\hline Rastrojo & Far & $4.56 \mathrm{a}$ & $0.70 b$ & $13.84 \mathrm{a}$ & $354.12 \mathrm{a}$ & $5.14 \mathrm{a}$ & $205.27 \mathrm{a}$ & $3.43 \mathrm{a}$ & $42.90 \mathrm{a}$ & $6.09 \mathrm{a}$ \\
\hline
\end{tabular}

CO: Carbono orgánico por Walkley-Black; CIC: Capacidad de intercambio catiónico en Acetato de Amonio normal y neutro ; Pt: Fósforo total; Ps:Fósforo soluble; Po: Fósforo orgánico; PAl: Fósforo unido al aluminio; PFe: Fósforo unido al hierro; PCa: Fósforo unido al calcio. Pt y demás fracciones de fósforo fueron determinadas por Bray II Medias con la misma letra en sentido vertical, no difieren estadísticamente según prueba de Tukey (alpha=0.1) 
Tabla 2 - Comparación del ADN total del suelo y las esporas de HMA a dos profundidades en suelos del sur de la Amazonia colombiana .

\begin{tabular}{lllll}
\hline Profundidad (cm) & $\begin{array}{l}\text { ADN total del suelo } \\
\text { (nanogramo/g suelo) }\end{array}$ & $\begin{array}{l}\text { No. Esporas HMA/100 } \\
\text { g suelo }\end{array}$ & $\begin{array}{l}\text { No Morfotipos esporas HMA por } \\
\text { muestra }\end{array}$ & $\begin{array}{l}\text { No. Morfotipos esporas HMA por } \\
\text { profundidad }\end{array}$ \\
\hline 20 & $57.2 \mathrm{a}$ & $477.3 \mathrm{a}$ & $4.1 \mathrm{a}$ & $14 \mathrm{a}$ \\
30 & $23.6 \mathrm{~b}$ & $87.6 \mathrm{~b}$ & $2.6 \mathrm{~b}$ & $15 \mathrm{a}$ \\
\hline
\end{tabular}

Medias con la misma letra en sentido vertical, no difieren estadísticamente según prueba de Tukey (alfa $=0.10)$

baja importancia que la fase mineral del suelo tiene en el aporte de nutrientes para los organismos edáficos y las plantas.

El estudio de HMA a partir de las esporas recobradas de muestras de suelo puede no reflejar fielmente la comunidad de estos hongos, dado que muchos de estos no esporulan (Sanders et al., 1996) o la producción de esporas está condicionada a los cambios edáficos del suelo. A pesar de ello, la cuantificación de esporas de HMA sigue siendo la forma mas sencilla de evaluar las poblaciones de micorrizas en el suelo (Cuenca et al., 1998), mas en un ecosistema en donde no se presenta una especificidad ecológica por la alta diversidad de hospederos y donde el clima es poco variable durante el año y se presume que estas variables no influyen en la producción de esporas del hongo (Janos, 1996).

La relación entre el contenido de $\mathrm{ADN}$ del suelo y la concentración de esporas de hongos micorrícicos arbusculares, se explicó a partir de un modelo de regresión lineal simple $(\mathrm{ADN}=20,897+0,084$ Número de esporas), seleccionado por ser el de mejor ajuste entre todos los modelos propuestos a un nivel de significancia de $\propto=0.05$ y con un coeficiente de determinación de 51.3\%. El haber encontrado este modelo para una relación esperada entre dos variables a partir de datos de campo, motivó a buscar otras relaciones de interés entre variables.

Se realizaron entonces análisis de regresión para explicar el comportamiento de las variables biológicas, en función de las variables químicas del suelo, permitiendo ajustar dos modelos de regresión a un nivel de significancia de $\propto=0.05$ : Uno para la concentración de ADN con un coeficiente de determinación del $62 \%$, y otro para el número de esporas con un coeficiente de determinación de $55.5 \%$. Los modelos obtenidos son:

$\mathrm{ADN}=34.3 \mathrm{pH}+7.73 \% \mathrm{P}$ unido al aluminio -145.14

No. de esporas $=517 \mathrm{pH}+55.36 \% \mathrm{P}$ unido al hierro 2823.62

Como se puede observar, el $\mathrm{pH}$ presenta un efecto significativo sobre el contenido de ADN y el número de esporas presentes en el suelo. Un ligero aumento del $\mathrm{pH}$ en el suelo genera una menor saturación de aluminio y una mejor capacidad de intercambio catiónico de las arcillas, reduciendo el estrés en las poblaciones biológicas del suelo, lo que se traduce en un aumento de sus densidades poblacionales, y en el caso de los hongos micorrícicos, favoreciendo la esporulación.

La primera ecuación permite predecir que en condiciones de acidez extremas pero posibles en el suelo (un $\mathrm{pH}$ de 3.0 o ligeramente menor), donde igualmente habría una alta quelación de fósforo en las arcillas, evidenciado por el fosfato de aluminio en altas concentraciones (cercano a 5 ppm), la cantidad de ADN (organismos vivos en el suelo) tendería a ser cercano a cero. La ecuación no tiene en cuenta que existe una pérdida de $\mathrm{ADN}$ en el proceso de extracción inherente a la metodología y que aquí no se cuantifica, pero se asume que existe y que debe ser homogéneo para todas las muestras, causando un sesgo en el valor predicho pero no en la relación encontrada entre las variables.

Se encontró además que la esporulación de los HMA, es afectada tanto por el $\mathrm{pH}$ como por el fósforo unido al hierro. Las fracción de fósforo mas abundante en estos suelos es la orgánica que corresponde al 40-70\% del fósforo total, sin embargo, su disponibilidad es baja dada la alta acidez y la formación de fosfatos de hierro y aluminio que corresponden a formas muy estables de difícil disolución. Los fosfatos de hierro tienen a formarse con mayor frecuencia, correspondiendo al 10-15\% del fósforo existente, mientras los fosfatos de aluminio y calcio solo representan el 1-2\% del fósforo total (IGAC 1997a; IGAC 1997b).

La segunda ecuación indica que a $\mathrm{pH}$ ácidos (no menores al pH estimado para la primera ecuación), donde los fosfatos de hierro son los más abundantes, la producción de esporas aumentará proporcionalmente a la cantidad de fósforo fijado al hierro. La relación directa existente entre la cantidad de esporas en el suelo y la cantidad de fosfatos de hierro, podría ser explicada por la solubilización de fosfatos que permite una mayor disponibilidad de fósforo para la producción de esporas. La solubilización sería atribuida directamente a las micorrizas arbusculares o a microorganismos de vida libre que actúan sinérgicamente con las micorrizas arbusculares.

La solubilización directa de fosfatos ha sido documentada en hongos formadores de ectomicorrizas pero no en hongos formadores de micorrizas arbusculares (Moyersoen, 1993; 
Smith y Read, 1997; Moyersoen et al., 2001) por cuanto la primera hipótesis en principio es descartada. Diversos autores han reportado que las micorrizas arbusculares aumentan la eficiencia en la absorción de fósforo mineral (Cui y Caldwell, 1997; Ozinga et al., 1997), a partir del fósforo solubilizado por otros microorganismos que actúan sinérgicamente (Osorio y Habte, 2001; Villegas y Fortin, 2001).

La mayoría de los estudios que demuestran un efecto positivo en las plantas al inocular conjuntamente hongos micorriza arbuscular con microorganismos solubilizadores de fosfatos, se han basado en la evaluación de la acción de poblaciones solubilizadoras de fosfatos de calcio (Kucey y Leggett, 1989; Singh y Kapoor, 1998; Ramirez et al., 2001) y no de solubilizadores de fosfatos de hierro, por no ser las formas frecuentes de fosfatos en suelos neutros o de baja acidez.

La solubilización microbiológica de fosfatos de hierro ha sido reportada (Brady y Weil citados por Cabrera (2000)). Esta solubilización también ocurre en suelos de la región amazónica (Vera, 1999; Cabrera, 2000), por lo que podría estar contribuyendo a la disponibilidad de fósforo en el suelo.
Sin embargo, se necesitan mas investigaciones que demuestren efectos significativos en el fósforo asimilado por las plantas a partir de la solubilización microbiológica de fosfatos de hierro, o la existencia de una relación sinérgica entre micorrizas arbuscualres y microorganismos solubilizadores de fosfatos de hierro, similar a la que ocurre entre las micorrizas arbusculares y los solubilizadores de fosfatos de calcio.

\section{COMPOSICIÓN DE HMA DE LOS SUELOS}

La composición micorrícica de los suelos bajo diferentes coberturas fue diferente dado que la vegetación, como hospedero obligado de las micorrizas arbusculares, tiene un efecto directo sobre la diversidad de sus poblaciones (Schenck et al., 1989; Рeña-Venegas, 2001). En este estudio se encontraron 18 morfotipos de esporas de HMA diferentes (Tabla 3): 11 especies de Glomus, 4 especies de Acaulospora, y una especie de Archaeospora, Scutellospora y Gigaspora. Diversos autores han mostrado como los géneros más representativos de suelos tropicales húmedos de textura arcillosa a francoarcillosa son Glomus y Acaulospora, siendo los géneros Gigaspora y Scutellospora los menos frecuentes (Bhatia et al., 1996). Esta estructura en la composición micorrícica de los

Tabla 3 - Riqueza y abundancia de especies de Glomales bajo tres coberturas diferentes en suelos del sur de la Amazonia colombiana

\begin{tabular}{|c|c|c|c|c|c|c|c|c|c|c|c|}
\hline COBERTURA & & 1s & $1 p$ & $2 s$ & $2 p$ & $3 \mathrm{~s}$ & $3 p$ & $4 s$ & $4 p$ & $5 s$ & $5 p$ \\
\hline \multirow[t]{20}{*}{ BOSQUE } & Esporas /100 g suelo & 203,3 & 46,6 & 643,3 & 65 & 393,3 & 33,3 & 375 & 136,6 & 326,6 & 86,6 \\
\hline & Número especies & 4 & 3 & 8 & 5 & 6 & 3 & 4 & 4 & 5 & 3 \\
\hline & Glomus sp1 & 42,5 & 27,3 & 27,8 & 26,3 & 20,6 & 20,9 & 44,5 & 43,5 & 22,1 & 51,2 \\
\hline & Glomus sp2 & - & - & - & - & - & - & - & - & - & - \\
\hline & Glomus sp3 & - & - & - & - & - & - & - & - & - & - \\
\hline & Glomus sp4 & - & - & 4,7 & 7,0 & - & - & - & - & - & - \\
\hline & Glomus sp5 & - & - & 2,3 & - & 36,0 & - & - & - & - & - \\
\hline & Glomus sp6 & - & - & - & - & - & - & - & - & - & - \\
\hline & Glomus sp7 & - & - & - & - & 2,3 & 50,0 & - & - & - & - \\
\hline & Glomus sp8 & - & - & 8,4 & 35,1 & - & - & - & - & 2,3 & - \\
\hline & Glomus sp9 & 34,8 & 36,4 & 6,9 & 21,0 & 12,6 & 29,2 & 26,6 & 26,7 & 27,3 & 37,3 \\
\hline & G. viscosum & - & - & 9,2 & - & - & - & - & - & - & - \\
\hline & G. manihotis & - & - & - & - & - & - & - & - & - & - \\
\hline & Acaulospora sp. & - & - & 24,2 & - & - & - & - & 8,9 & - & - \\
\hline & A. tuberculata & - & - & - & - & - & - & - & - & - & 11,5 \\
\hline & A. morrowiae & - & - & - & - & 18,2 & - & - & - & 28,1 & - \\
\hline & A. foveata & 10,3 & - & - & - & 10,3 & - & 4,6 & - & - & - \\
\hline & Archaeospora leptoticha & 12,5 & 36,4 & 16,5 & - & - & - & 24,3 & - & 20,2 & - \\
\hline & $\begin{array}{l}\text { Scutellospora } \\
\text { pellucida }\end{array}$ & - & - & - & - & - & - & - & 20,9 & - & - \\
\hline & Gigaspora sp. & - & - & - & 10,6 & - & - & - & - & - & - \\
\hline RASTROJO & Esporas /100 g suelo & 210 & 73,3 & 526,6 & 50 & 160 & 90 & 150 & 116,6 & 386,6 & 230 \\
\hline
\end{tabular}


Tabla 3 - Continuación

\begin{tabular}{|c|c|c|c|c|c|c|c|c|c|c|c|}
\hline & Número especies & 4 & 2 & 6 & 4 & 4 & 3 & 5 & 6 & 5 & 7 \\
\hline & Glomus sp1 & 32,6 & 66,5 & 24,4 & 38,3 & 40,7 & 38,1 & 18,9 & 13,9 & 34,2 & 22,0 \\
\hline & Glomus sp2 & - & - & - & - & - & - & - & - & - & - \\
\hline & Glomus sp3 & - & - & - & - & - & - & 4,7 & - & - & - \\
\hline & Glomus sp4 & - & - & - & - & - & - & 18,9 & - & - & - \\
\hline & Glomus sp5 & 33,1 & - & - & 19,7 & 17,8 & - & - & - & - & - \\
\hline & Glomus sp6 & - & - & 5,7 & - & - & - & - & - & 15,5 & 15,4 \\
\hline & Glomus sp7 & - & - & - & - & - & - & 38,9 & - & 13,3 & 16,0 \\
\hline & Glomus sp8 & - & - & - & - & - & - & - & - & - & - \\
\hline & Glomus sp9 & 24,1 & 33,5 & 28,2 & 25,2 & 31,1 & 32,6 & 18,5 & 12,3 & - & 8,5 \\
\hline & G. viscosum & - & - & - & - & - & - & - & - & - & - \\
\hline & G. manihotis & - & - & - & - & - & - & - & 25,6 & - & - \\
\hline & Acaulospora sp. & - & - & - & - & - & - & - & 10,2 & - & 30,5 \\
\hline & A. tuberculata & - & - & - & - & - & - & - & - & - & 2,2 \\
\hline & A. morrowiae & - & - & 20,1 & - & - & - & - & 30,7 & - & - \\
\hline & A. foveata & - & - & 5,7 & 16,8 & 10,4 & - & - & 7,3 & 0,9 & 5,4 \\
\hline & Archaeospora leptoticha & 10,2 & - & 15,9 & - & - & 29,4 & - & - & 36,2 & - \\
\hline & Scutellospora pellucida & - & - & - & - & - & - & - & - & - & - \\
\hline & Gigaspora sp. & - & - & - & - & - & - & - & - & - & - \\
\hline \multirow[t]{20}{*}{ PRADERA } & Esporas /100 g suelo & 430 & 103,3 & 1023,3 & 126,6 & 683,3 & 63,3 & 356,6 & 20 & 1173,3 & 106,6 \\
\hline & Número especies & 5 & 5 & 5 & 4 & 6 & 4 & 5 & 1 & 6 & 5 \\
\hline & Glomus sp1 & 36,1 & 19,1 & 16,0 & 28,2 & 55,7 & 43,8 & 19,7 & 100,0 & 22,6 & 33,3 \\
\hline & Glomus sp2 & - & - & - & - & - & - & - & - & 8,9 & - \\
\hline & Glomus sp3 & - & - & - & - & - & - & 29,7 & - & 47,0 & - \\
\hline & Glomus sp4 & - & - & 26,0 & - & - & - & - & - & 11,3 & - \\
\hline & Glomus sp5 & - & - & - & - & 4,3 & - & 12,3 & - & - & - \\
\hline & Glomus sp6 & - & - & 20,0 & - & 14,6 & - & - & - & - & 29,2 \\
\hline & Glomus sp7 & 20,8 & - & 31,6 & 5,1 & 2,1 & - & - & - & 10,0 & - \\
\hline & Glomus sp8 & - & - & - & 33,3 & - & - & - & - & - & - \\
\hline & Glomus sp9 & 20,5 & 25,4 & - & 33,3 & 15,6 & 10,4 & 4,6 & - & 0,1 & 4,2 \\
\hline & G. viscosum & - & - & - & - & - & - & - & - & - & - \\
\hline & G. manihotis & - & - & - & - & - & - & - & - & - & 8,3 \\
\hline & Acaulospora sp. & - & - & - & - & - & - & - & - & - & - \\
\hline & A. tuberculata & - & - & - & - & - & - & - & - & - & - \\
\hline & A. morrowiae & - & 34,7 & - & - & - & - & 33,6 & - & - & - \\
\hline & A. foveata & 7,2 & 3,4 & - & - & 7,7 & 25,0 & - & - & - & - \\
\hline & Archaeospora leptoticha & 15,5 & 17,3 & 6,5 & - & - & 20,8 & - & - & - & - \\
\hline & Scutellospora pellucida & - & - & - & - & - & - & - & - & - & 25,0 \\
\hline & Gigaspora sp. & - & - & - & - & - & - & - & - & - & - \\
\hline
\end{tabular}

Los números del 1 al 5 corresponden a las cinco réplicas de cada una de las coberturas estudiadas. La letra s corresponde a la muestra tomada entre los $0-20 \mathrm{~cm}$ de profundidad de la réplica; la letra p corresponde a la muestra tomada entre los $20-30 \mathrm{~cm}$ de profundidad de la réplica. 
suelos ha sido igualmente reportada para la región amazónica venezolana (Cáceres, 1989), brasileña (Caproni et al., 2003), y en este trabajo para la Amazonia colombiana. De los tres trabajos anteriormente citados para la cuenca amazónica, se encuentra que el género Glomus representa mas del $50 \%$ de la diversidad micorrícica del suelo, Acaulospora mas del 20\% y los demás géneros porcentajes menores al $20 \%$, lo cual indica que la composición micorrícica de los suelos arcillosos de la Amazonia se mantiene a lo largo de toda la cuenca.

La composición micorrícica puede ser igualmente afectada por cambios en la composición florística del lugar. La pradera 5 mostró una composición micorrícica diferente a las otras cuatro, presentando un tipo de Glomus único para este lugar (Glomus sp2). La presencia de Glomus sp2, podría explicarse por la introducción de semillas de pastos foráneos que traerían asociado el hongo. La presencia de esta especie de hongo podría igualmente estar favoreciendo el establecimiento de Scutellospora pellucida en este suelo, dado que no fue recuperada en potreros donde Glomus sp9 era la segunda especie dominante.

Algunas especies estuvieron relacionadas con coberturas intervenidas como Glomus sp3, Glomus sp6 y Glomus manihotis. Esta última ha sido frecuentemente relacionada con cultivos, lo que muestra su capacidad de permanecer en el suelo asociado a plantas huésped, que no necesariamente fueron su huésped original. De hecho, esta especie en particular ha sido usada en experimentos de campo en zonas tropicales por su gran versatilidad al asociarse eficazmente con diferentes huéspedes (Bhatia et al., 1996; Cuenca et al., 2003).

\section{CONCLUSIONES}

El trabajo muestra diferencias significativas entre la cantidad de $\mathrm{ADN}$ y el número de esporas de HMA recuperadas a una profundidad de $0-20 \mathrm{~cm}$ que a $20-30 \mathrm{~cm}$. La relación entre la cantidad de ADN del suelo y el número de esporas de HMA pudo ser descrita a partir de un modelo de regresión linear simple.

El pH afecta tanto la cantidad de ADN como el número de esporas de HMA presentes en el suelo. La cantidad de ADN del suelo se vio afectado por las concentraciones de fosfatos de aluminio, mientras el número de esporas de HMA fue afectado pro las concentraciones de fosfatos de hierro en el suelo. Estas relaciones pudieron ser descritas a partir de modelos de regresión.

La evaluación de la composición micorrícica de los suelos identificó 18 especies de HMA de 5 géneros de Glomales: Glomus, Acaulospora, Scutellospora, Archaeospora y Gigaspora, en donde Glomus representa mas del 50\% de la población, Acaulospora mas del 20\%, y Archaeospora, Gigaspora y Scutellospora, aparecen con porcentajes menores al $20 \%$.
Esta estructura parece ser homogénea no solo para la zona de estudio, sino para todos los suelos arcillosos de la cuenca amazónica.

\section{AGRADECIMIENTOS}

Agradecemos a la Dra. Gisela Cuenca del Laboratorio de Ecología de Suelos del Instituto Venezolano de Investigaciones Científicas (IVIC) por su dedicación y apoyo en la revisión de los morfotipos de esporas de hongos micorrícicos y su determinación taxonómica.

\section{BIBLIOGRAFIA CITADA}

Bhatia, N. P.; Sundari, K.; Adholeya, A. 1996. Diversity and selective dominance of vesicular-arbuscular mycorrhizal fungi. In: K. G. Mukerji (Ed). Concepts in Mycorrhizal Research. Kluwer Academic Publishers. p. 133-178.

Borneman, J.; Triplett, E.W. 1997. Molecular microbial diversity in soils from eastern Amazonia: evidence for unusual microorganisms and microbial population shifts associated with deforestation. Applied and Environmental Microbiology, 67(3): 2647-2653.

Cabrera, T.A. 2000. Aporte al conocimiento de la microflora fúngica del suelo de la Amazonía Colombiana, con énfasis en tres grupos funcionales. Tesis de Pregrado. Facultad de Biología, Universidad Nacional de Colombia, Bogotá, Colombia. 283 pp.

Cáceres, A. 1989. Las micorrizas vesiculo-arbusculares en un bosque húmedo tropical y su evolución luego de la perturbación (conuco) y la sucesión por 60 años en San Carlos de Río Negro. Tesis de Maestría. Centro de Estudios Avanzados, Instituto Venezolano de Investigaciones Científicas IVIC, Caracas, Venezuela. 252pp.

Cho, J.; Lee, D.; Cho, Y.; Cho, J.; Kim, S. 1996. Direct extraction of DNA from soil for amplification of $16 \mathrm{~S}$ rRNA gene sequences by polymerase chain reaction. J. Microbiology, 34(3): 229-235.

Caproni, A.L.; Franco, A.A.; Berbara, R.L.L.; Truferri, S.B.; De Oliveira, J.R.D.; Monteiro, A.B. 2003. Ocorrência de fungos micorrizicos arbusculares en áreas revegetadas após mineração de bauxita en Porto Trombetas, Pará. Pesq. Agropec. Bras. Brasilia 38(12): 1409-1418.

Cuenca, G.; De Andrade, Z.; Escalante, G. 1998. Diversity of Glomalean spores from natural, disturbed and revegetated communities growing on nutrient-poor tropical soils. Soil Biol. Biochem, 30(6): 711-719.

Cuenca, G.; De Andrade, Z.; Meneses, E. 2001. The presence of aluminum in arbuscular mycorrhizas of Clusia multiflora exposed to increased acidity. Plant and Soil, 231: 233-241.

Cuenca, G.; De Andrade, Z.; Lovera, M.; Fajardo, L.; Meneses, E. 2003. Mycorrhizal response of Clusia pusilla growing in two different soils in the field. Trees, 17: 200-206.

Cuevas, E. 2001. Soil versus biological controls on nutrient cycling in Terra Firme Forests. In: M.E. McClain, R.L. Victoria, J.E. Richey (Eds). The biochemistry of Amazon basin. Oxford University Press. p. 53-67. 
Cui, M.; Caldwell, M.W. 1997. Shading reduces exploitation of soil nitrate and phosphate by Agropyron desertorum and Artemisia tridentata from soils with patchy and uniform nutrient distributions. Oecologia, 109: 177-183.

Diederichs, Chr.; Moawad, A.M. 1993. The potencial of VA Mycorrhizae for plant nutrition in the tropics. Angew. Bot., 67: 91-96.

Dodd, J.C; Arias, I.; Koomen, I.; Hayman, D.S. 1990. The management of populations of vesicular-arbuscular micorrhizal fungi in acid-infertile soils of a savanna ecosystem. I. The effect of pre-cropping and inoculation with VAM fungi on plant growth and nutrition in the field. Plant and Soil, 122: 229-240.

Gerdemann, J.W.; Nicolson, T.H. 1963. Spores of mycorrhizal Endogone species extracted from soil by wet sieving and decanting. Transactions of the British Mycological Society, 46: 235-244.

Instituto Geográfico Agustín Codazzi - IGAC-. 1997a. Zonificación Ambiental para el Plan Modelo Colombo - Brasilero (Eje Apaporis - Tabatinga: PAT). Bogotá, Colombia. p. 169-182.

Instituto Geográfico Agustín Codazzi - IGAC-. 1997b. Investigaciones para la Amazonia - INPA III. Segundo informe de avance. Bogotá, Colombia. p. 37-44.

International Culture Collection Of Arbuscular Mycorrhizal Fungi IVAM. 2003. http://invam.caf.wvu.edu/. Acceso: 10/11/03.

Howeler, R.H.; Sieverding, E. 1982. La importancia de las micorrizas en la absorción de fósforo por la yuca. Suelos Ecuatoriales, 12(2): 182-193.

Janos, D.P. 1983. Tropical micorrhizas, nutrient cycles and plant growth. In: L. Sutton, T.C. Whitmore, A.C. Chadwick (Eds). Tropical Rain Forest: Ecology and Management.

Blackwell Scientific Publications. Oxford, England. p. 327-345.

Janos, D.P. 1996. Mycorrhizas, succession, and the rehabilitation of deforested lands in the humid tropics. In: J. C. Frankland, N. Magan, G. M. Gadd (Eds). Fungi and Enviromental Change. p. 129-162.

Johnsen, K.; Enger, O.; Jacobsen, C.S.; Thirup, L.; Torsvik, V. 1999. Quantitative selective PCR of 16 S ribosomal DNA correlates well with selective agar plating in describing population dynamics of indigenous Pseudomonas spp. in soil hot spots. Applied and Environmental Microbiology, 65(4): 1786-1789.

Kucey, R.M.N.; Leggett, M.E. 1989. Increased yields and phosphorus uptake by westar canola (Bassica napus L.) inoculated with a phosphate-solubilizing isolate of Penicillium bilaji. Canadian Journal of Soil Science 69: 425-432.

Martin-Laurent, F.; Philippot, L.; Hallet, S.; Chaussod, R.; Germon, J.C.; Soulas, G.; Catroux, G. 2001. DNA extraction from soils: old bias for new microbial diversity analysis methods. Applied and Environmental Microbiology, 67(5): 2354-2359.

Moyersoen, B. 1993. Ectomicorrizas y micorrizas vesiculoarbusculares en Caatinga Amazónica del Sur de Venezuela. Scientia Guaianae, 3: 82pp.

Moyersoen, B.; Becker, P.; Alexander, I.J. 2001. Are ectomycorrhizas more abundant than arbuscular mycorrhizas in tropical heath forests?. New Phytologist, 150: 591-599.
Osorio, N.W.; Habte, M. 2001. Synergistic influence of an arbuscular mycorrhizal fungus and a P solubilizing fungus on growth and $\mathrm{P}$ uptake of Leucaena leucocephala in an Oxisol. Arid Land Research and Management, 15: 263-274.

Ozinga, W.A.; Van Andel, J.; Mcdonnell-Alexander, M.P. 1977. Nutritional soil heterogeneity and mycorrhiza as determinants of plants species diversity. Acta Bot. Neerl., 46(3): 237-254.

Peña-Venegas, C.P. 2001. Dinámica de la comunidad micorriza arbuscular en bosques de la Amazonia sur de Colombia. Suelos ecuatoriales, 31(1): 103-107.

Picard, C.; Ponsonnet, C.; Paget, E.; Nesme, X.; Simonet, P. 1992. Detection and enumeration of bacteria in soil by direct DNA extraction and polymerase chain reaction. Applied and Environmental Microbiology, 58(9): 2717-2722.

Ramírez, A.; Otalvaro, D.; Alvarez, C.; Pérez, J.C.; Osorio, N.W. 2001. Efectos de organismos rizosféricos sobre la absorción de fosfato y el crecimiento de Leucaena en un Andisol. Suelos Ecuatoriales, 31(2): 239-243.

Saldarriaga, J.G. 1991. Recuperación de la selva de "Tierra Firme" en el alto Río Negro Amazonia Colombiana-Venezolana. En: TROPENBOS (Ed). Estudios en la Amazonia colombiana. Vol. V., Colombia. 221pp.

Sanders, I.R.; Clapp, J.P.; Wiemken, A. 1996. The genetic diversity of arbuscular mycorrhizal fungi in natural ecosystems - A key to understanding the ecology and functioning of the mycorrhizal symbiosis. New Phytologist, 133: 123-134.

Schenck, N.C.; Siqueira, J.O.; Oliveira, E. 1989. Changes in the incidence of VA mycorrhizal fungi with changes in ecosystems. In: V. Vancura, F. Kunc. (Eds). Interrelationships between microorganisms and plants in soil. Amsterdam, Elsevier. p. 125129.

Schenck, N.C.; Y. Perez. 1988. Manual for the identification of VA micorrhizal fungi. International Culture Collection of Arbuscular Mycorrhizal Fungi - INVAM. University of West Virginia. 241pp.

Schlesinger, W.H. 1997. Biogeochemistry: An analysis of global change. Academic Press, San Diego CA, USA. 588pp.

Sieverding, E. 1984. Aspectos básicos de la investigación de la micorriza vesiculo-arbuscular (MVA). Primer Curso Nacional sobre Micorrizas. Facultad de Ciencias Agropecuarias-Palmira. Memórias. p. 86-87.

Singh, S.; Kapoor, K.K. 1998. Effects of inoculation of phosphatesolubilizing microorganisms and arbuscular mycorrhizal fungus on mung bean grown under natural soil conditions. Mycorrhiza, 7(5): 249-253.

Smith, S.E.; Read, D.J. 1997. Mycorrhizal symbiosis. London, UK. Academic Press. p. 11-32.

St. John, T.V. 1980. A survey of mycorrhizal infection in an amazonian rain forest. Acta Amazonica, 10(3): 527-533.

Vera, D. 1999. Aislamiento y caracterización de hongos solubilizadores de fosfatos de la rizósfera de Arazá (Eugenia stipitata) en dos unidades fisiográficas del Departamento del Guaviare. Tesis 
de Pregrado. Facultad de Biología, Universidad Nacional de Colombia, Bogotá, Colombia. 233 pp.

Villegas, J.; Fortin, J.A. 2001. Phosphorus solubilization and $\mathrm{pH}$ changes as a result of the interactions between soil bacteria and arbuscular mycorrhizal fungi on a medium containing $\mathrm{NH}_{4}^{+}$as nitrogen source. Can. J. Bot., 79: 865-870.

Vitousek, C. 1984. Litterfall nutrient cycling and nutrient limitation in tropical forests. Ecology, 65: 285-298.
Wenzl, P.; Hill, P.; Jones, P.; Gallego, G.; Tohme, J. 1997. An enzimatic method for the direct extraction of bacterial ADN from soil. CIAT. Cali-Colombia.

Recebido en 04/12/2003

Acepto en 21/05/2007 